\title{
Is Thermogravimetry an efficient alternative to gas chromatography in degree of biodiesel conversion?
}

\author{
Caroline Gaglieri $^{1} \cdot$ Rafael T. Alarcon ${ }^{1} \cdot{\text { Aniele de } \text { Moura }^{2} \cdot \text { Roni A. Mendes }}^{3}$ - Flávio J. Caires ${ }^{1,2}$
}

Received: 30 January 2018 / Accepted: 7 May 2018/Published online: 17 May 2018

(C) Akadémiai Kiadó, Budapest, Hungary 2018

\begin{abstract}
This work aims to determine if thermogravimetry could be used to determine the degree of conversion of soybean oil to biodiesel without knowing the amount of ester in the sample, comparing the results with the values obtained by the standard method, gas chromatography. The syntheses were made using homogeneous and heterogeneous catalysts, and the measures were made in triplicate on both pieces of equipment. The average values (\%) obtained were $74.59 \pm 0.58$, $66.5 \pm 1.62,13.54 \pm 0.32$ by thermogravimetry and $74.09 \pm 0.46,62.08 \pm 2.19,17.07 \pm 0.31$ by gas chromatography. These data were statistically compared using $F$-test, and the result indicated that the thermogravimetry could be used as analytical technique to determine the degree of conversion of biodiesel, with the same reliability as gas chromatography. The thermogravimetry shows more advantages than gas chromatography, because it does not require organic solvent, following the Green Chemistry Principles, and it is already used to determine other thermal properties of biodiesel.
\end{abstract}

Keywords Biodiesel · Degree of conversion · Thermogravimetry · Gas Chromatography · Green Chemistry

\section{Introduction}

Biodiesel is considered as a biofuel and a substitute of diesel $[1,2]$. The growing biodiesel demand has caused increased global production, which could expand $24.0 \%$ by 2024 compared to 2014 [3]. Gas Chromatography (GCFID) is the standard method to determine the degree of feedstock conversion to biodiesel in most countries, as determine by the standards $[4,5]$. These standards establish the use of organic solvents, such as n-heptane and toluene; however, both are not completely green solvents according to Green Chemistry [6, 7]. Hence, a technique that does not use any solvent is strongly recommended considering the

The present article is based on the lecture presented at SiAT VIII conference in Punta Grossa - Brazil on August 13-15, 2017.

Flávio J. Caires

caires.flavio@fc.unesp.br

1 Chemistry Department, School of Sciences, São Paulo State University (UNESP), Bauru, SP 17033-260, Brazil

2 Institute of Chemistry, São Paulo State University (UNESP), Araraquara, SP 14800-060, Brazil

3 Science and Technology Institute, UNIFAL-MG, Poços de Caldas, MG 37715-400, Brazil environmental aspects. Thermogravimetry (TG) is an excellent choice, due to the absence of solvents. Moreover, this thermal analysis technique is already used to determine other properties of biodiesel, such as thermal stability, moisture content, oxidation, purity [8-16], which reduce the total time to characterize the biodiesel. The reduction in analysis time, the nonuse of solvent, and the non-generation of effluent (considering that in CG-FID analysis the solution n-heptane and biodiesel are discarded) of the TG technique are in agreement with the Green Chemistry [7].

This technique was previously mentioned in the literature to quantify biodiesel content in mixtures and compare the results obtained by Proton Nuclear Magnetic Resonance ( $\left.{ }^{1} \mathrm{H}-\mathrm{NMR}\right)$ [17] and by GC-FID [18] without use of any statistic method. In both works, the TG curves were made under nitrogen atmosphere, which could interfere in thermal stability difference between soybean oil and biodiesel. However, in Ref. [17], the authors did not specifically determine the degree of conversion, or an equation to determine this variable, or compare the results obtained with the standard method (GC-FID). In Ref. [18], the authors proposed one equation and conclude that the TG could be used just for biodiesel with high ester content and when the degree of conversion was less than $30.0 \%$ the comparative error was equal to $55.8 \%$, which is considered 
a high value. Moreover, the authors did not consider the isolated compounds (biodiesel and oil) in their analytic curve.

Therefore, this work aims to investigate if the use of TG is valid for determining the degree of biodiesel conversion, without knowing the amount of ester in the sample. One equation was proposed, considering the isolated compounds, and the TG and GC-FID results were compared using the $F$-test as a statistic tool.

\section{Materials}

The soybean oil (food grade) was purchased from a local market. All chemicals were of analytical grade and were purchased from Sigma-Aldrich. The precursors of heterogeneous catalyst were calcium carbonate $\left(\mathrm{CaCO}_{3}\right)$ and strontium nitrate $\left(\mathrm{Sr}\left(\mathrm{NO}_{3}\right)_{2}\right)$, while the homogeneous catalyst was sulfuric acid $\left(\mathrm{H}_{2} \mathrm{SO}_{4}\right)$. The methyl esters used as external standards in GC-FID were stearate, palmitate, oleate, linoleate, and linolenate.

\section{Experimental}

\section{Catalyst preparation}

The heterogeneous catalysts calcium oxide $(\mathrm{CaO})$ and strontium oxide $(\mathrm{SrO})$ were prepared calcining the precursors $\mathrm{CaCO}_{3}$ and $\mathrm{Sr}\left(\mathrm{NO}_{3}\right)_{2}$ at $950.0{ }^{\circ} \mathrm{C}$ for $3 \mathrm{~h}$ under air atmosphere.

\section{Biodiesel preparation}

The experimental conditions were based on a previous work [19], the molar proportion oil/alcohol (1:6), and the mass of oil used $(50 \mathrm{~g})$ were the same. The time for heterogeneous catalysis reaction was $4.0 \mathrm{~h}$ using $\mathrm{CaO}$ and $\mathrm{SrO}$, while to homogenous synthesis was used 1 and $6 \mathrm{~h}$ for sodium hydroxide $(\mathrm{NaOH})$ and $\mathrm{H}_{2} \mathrm{SO}_{4}$. The amount of catalyst used in heterogeneous and homogeneous synthesis was 5.0 and 1.0 mass\%, respectively, in relation to soybean oil mass.

\section{Mixture preparation}

Five mixtures were prepared with biodiesel percentage varying between 0 and 100 mass\%. The mixtures were made to simulate the non-reacted soybean oil in transesterification reaction. The samples were named according to the percentage of biodiesel to soybean oil, for example: the system with 50 mass\% biodiesel was called 50 BD:50 SO. Thereby, all samples names were: 100 BD:0 SO; 75 BD:25
SO; 50 BD:50 SO; 25 BD:75 SO, and 0 BD:100 SO. These samples were just used in TG analysis to obtain Eq. 1, which will be explained later.

\section{Thermogravimetry (TG)}

The TG curves for each sample were obtained using the thermal analysis system from Netzsch, model STA 449 F3. Approximately $27.0 \mathrm{mg}$ of sample were measured and placed in a $70 \mu \mathrm{L} \alpha$-alumina open crucible. The parameters were set at a heating rate of $10.0{ }^{\circ} \mathrm{C} \mathrm{min}^{-1}$, and a flow rate of $50.0 \mathrm{~mL} \mathrm{~min}^{-1}$ in a dry air atmosphere. The temperature ranged from $30.0{ }^{\circ} \mathrm{C}$ to $650.0{ }^{\circ} \mathrm{C}$. The derivative of TG curve (DTG) was used to facilitate the understanding of the thermal step and to obtain the maximum degradation rate in the first decomposition stage.

\section{Gas Chromatography with flame ionization detector (GC-FID)}

The GC-FID analyses were performed in Perkin Elmer equipment model CG-Claurus, using the Elite-WAX Capillary Column $(30.0 \mathrm{~m} / 0.25 \mathrm{~mm} / 0.25 \mu \mathrm{m})$, with flame ionization detector (FID). The soybean oil samples were prepared according to the method previously reported [20] to quantify the methyl esters in raw material. The experimental conditions and quantification of methyl esters in biodiesel samples followed the literature [4] and [21], respectively.

\section{Statistical analysis}

The results obtained from the both techniques were analyzed by the $F$-test, which is a statistical test to compare two variances. The test was performed following the steps described by Ref. [22].

\section{Results and discussion}

The TG curves for each BD:SO mixture are presented together in Fig. 1a. The biodiesel was obtained by homogenous catalysis, and the GC-FID analysis indicates 99.93\% conversion. The biodiesel without addition of soybean oil (100 BD:0 SO) was thermally stable until $160.8^{\circ} \mathrm{C}$. This first step is associated with biodiesel evaporation followed by degradation (confirmed by a test tube, visual test) and ends at $312.1{ }^{\circ} \mathrm{C}$, the temperature that practically all biodiesel mass was already loosed (95.64\%). The second step of mass loss $(4.36 \%)$ occurred continuously and slowly, between 312.1 and $533.0{ }^{\circ} \mathrm{C}$, which is related to carbonized residue, as observed in the qualitative analysis in the test tube (visual test). Similar thermal 

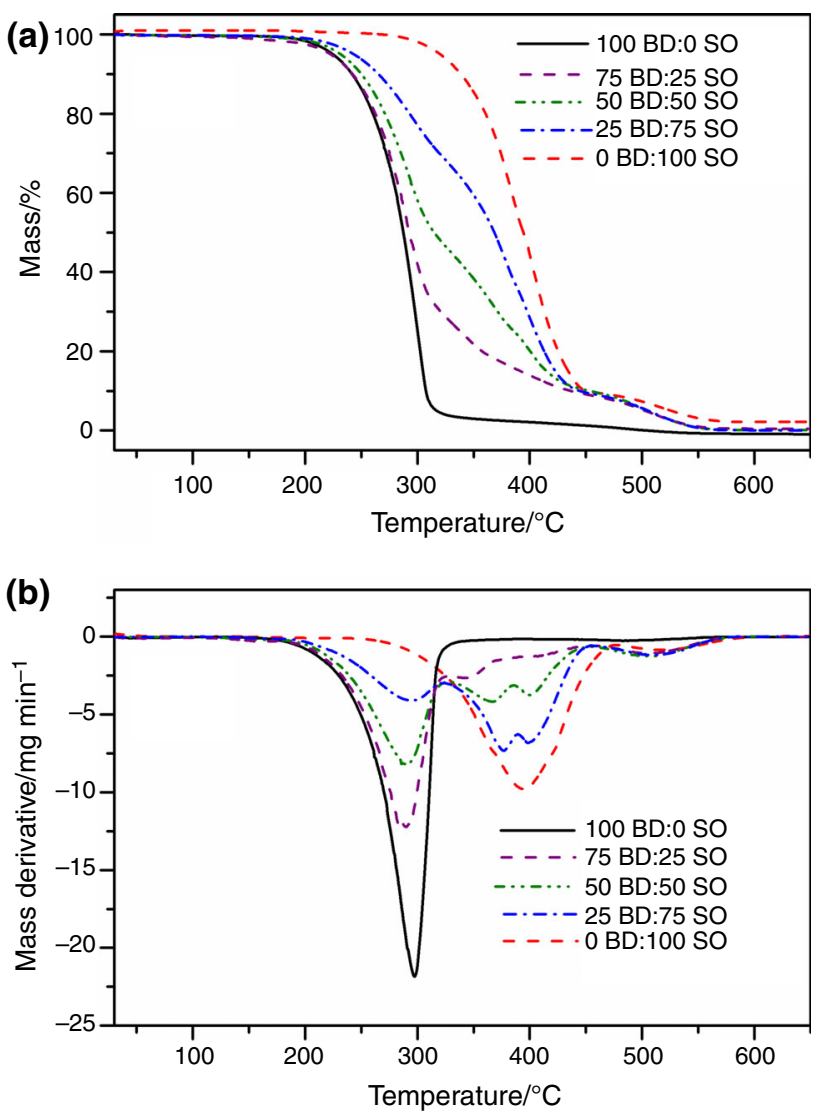

Fig. 1 TG (a) and DTG curves (b) of mixtures BD:SO varying the content of biodiesel between 0 and 100\%

behavior was observed in soybean oil without addition of biodiesel (0 BD:100 SO); however, the feedstock showed a thermal stability higher than biodiesel. The first mass loss (90.84\%) occurred in the range of 266.5 and $463.7^{\circ} \mathrm{C}$, and the second $(9.16 \%)$ between 463.7 and $587.9^{\circ} \mathrm{C}$.

The TG curves of samples 75:25; 50:50; and 25:75 (BD:SO) are shown in Fig. 1a. The mixtures with different biodiesel amount $(75,50$ and $25 \%)$ exhibited thermal stability equal to $164.3,168.5$ and $167.9^{\circ} \mathrm{C}$, respectively. These values were very similar to biodiesel without addition of soybean oil, as expected. Nevertheless, the DTG curves (Fig. 1b) show four steps of mass loss, rather than the two observed in the isolated compounds (100:0 and 0:100). The first and last mass losses are attributed to biodiesel without addition of soybean oil and to soybean oil without addition of biodiesel, respectively. The second step refers to degradation overlapping of two oils. Figure $1 \mathrm{~b}$ presents the derivative of mass loss curves (DTG) for each mixture. Except for the sample 100\% soybean oil, the samples $100: 0 ; 75: 25 ; 50: 50$, and 25:75 have a maximum peak at 283.9; $282.6 ; 284.5$, and $293.0^{\circ} \mathrm{C}$, respectively, associated to biodiesel degradation. With the increase in soybean oil ratio in the mixture, this peak decreases and a second peak occurs around $366.5^{\circ} \mathrm{C}$, evidencing the overlap of compounds in the second mass loss. The displacement of the second peak in the DTG curves to higher temperatures occurs until this peak meets the third peak (around $399.9{ }^{\circ} \mathrm{C}$ ), which refers only to soybean oil decomposition. In the 0 BD:100 SO sample, this both peaks become one wide peak at $396.8^{\circ} \mathrm{C}$.

The mass loss obtained until $312.1{ }^{\circ} \mathrm{C}$ and the maximum degradation rate $\left(\mathrm{DR}_{\max }\right)$ observed for each sample are shown in Table 1. The $\mathrm{DR}_{\max }$ value decreases with increased soybean oil, indicating that this decomposition step is mostly from biodiesel. The mass loss until $312.1{ }^{\circ} \mathrm{C}$ can be correlated with the biodiesel amount, due to this temperature almost biodiesel was already degraded $(95.62 \%)$, and then, its amount is proportional to mixtures (25:75; 50:50 and 25:75). A linear adjustment in these data can be made by equation (Eq. 1), which could be used to determine the degree of conversion (DC) of soybean oil to biodiesel.

The DC variable indicates the degree of conversion of soybean oil to biodiesel, and $x$ is the mass loss (\%) observed in the TG curve until $312.1{ }^{\circ} \mathrm{C}$. The number 4.55 refers to mass loss of isolated soybean oil until $312.1{ }^{\circ} \mathrm{C}$ and the numbers 0.86496 and 4.668 present in Eq. (1) are the angular and linear coefficients, respectively, and the both values were obtained by linear regression of the experimental data.

$\mathrm{DC}(\%)=0.86496(x-4.55)+4.668$

The values of linear $\left(R^{2}\right)$ and Pearson $(\rho)$ coefficients obtained from the linear adjustment equal to 0.99473 and 0.99803 , respectively, indicating that the adjustment could be considered good and there is a strong correlation between the variables. The resulting graphic of liner adjustment is shown in Fig. 2.

In Refs. [17] and [18], the authors did not consider the isolated compounds to determine the amount of biodiesel in their transesterification products. However, as observed in Fig. 1a that the SO already started its decomposition before all biodiesel decomposes and this decomposition practically is not noted in SO DTG curve, as observed in Fig. 1b. This information becomes more evident in

Table 1 Mass loss $(\Delta m)$ and maximum degradation rate $\left(\mathrm{DR}_{\max }\right)$ observed until $312.1^{\circ} \mathrm{C}$ for each mixture

\begin{tabular}{llll}
\hline BD:SO & Sample mass $/ \mathrm{mg}$ & $\Delta m\left(312.1^{\circ} \mathrm{C}\right) / \%$ & $\mathrm{DR} / \mathrm{mg} \mathrm{min}^{-1}$ \\
\hline $100: 0$ & 27.21 & 95.62 & 23.00 \\
$75: 25$ & 27.07 & 70.29 & 13.24 \\
$50: 50$ & 27.05 & 53.22 & 8.51 \\
$25: 75$ & 27.10 & 31.65 & 4.11 \\
$0: 100$ & 27.36 & 7.31 & - \\
\hline
\end{tabular}




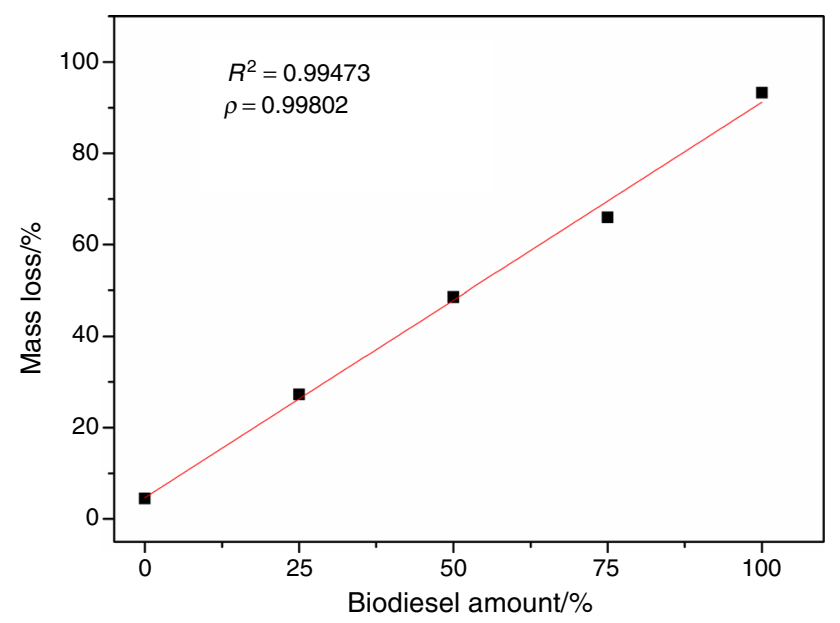

Fig. 2 Resulting graphic of linear adjustment

Table 1, which shows the mass loss of SO until $312.0{ }^{\circ} \mathrm{C}$ equal to $4.55 \%$. Hence, is very important made an equation to determine the DC also considering the isolated compounds, and not just the mixtures between $\mathrm{SO}$ and $\mathrm{BD}$.

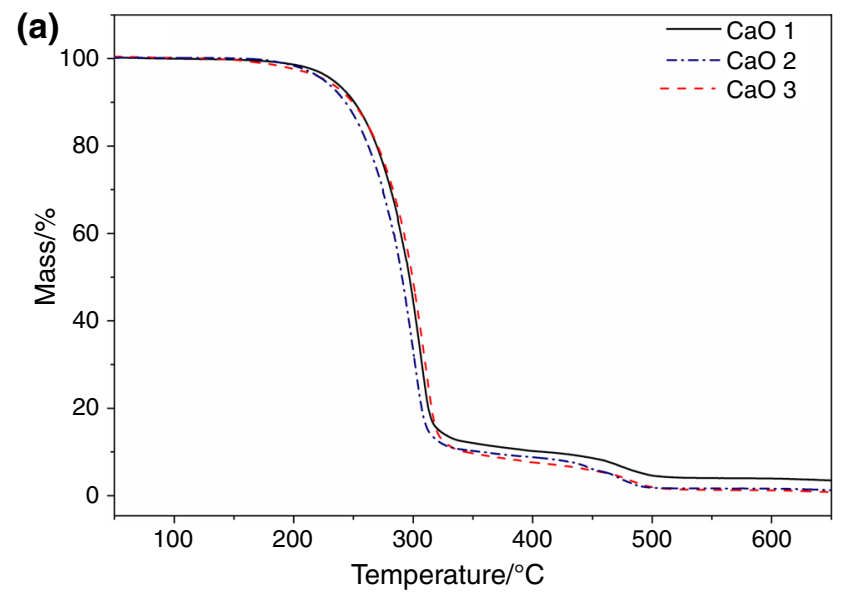

To test Eq. 1, the transesterification reaction was done using sulfuric acid $\left(\mathrm{H}_{2} \mathrm{SO}_{4}\right)$ as homogeneous catalyst and the oxides $\mathrm{CaO}$ and $\mathrm{SrO}$ as heterogeneous catalysts. Each transesterification product was analyzed in triplicate by $\mathrm{TG}$ and GC-FID analyses. The TG curves and chromatograms obtained using the homogeneous $\left(\mathrm{H}_{2} \mathrm{SO}_{4}\right)$ and heterogeneous $(\mathrm{CaO}$ and $\mathrm{SrO})$ catalysts are presented in Figs. 3 and 4 , respectively. The peaks numbered in chromatograms from 1 to 5 are associated to meanly methyl esters founded in soybean oil: palmitate, stearate, oleate, linoleate, and linolenate, respectively. To clarify the difference in thermal behavior of samples, Fig. 5 exhibits the TG curve of biodiesel obtained using each catalyst $(\mathrm{NaOH}, \mathrm{CaO}, \mathrm{SrO}$ and $\mathrm{H}_{2} \mathrm{SO}_{4}$ ), as well as the curve of soybean oil. It is noted that according to the decreases in DC, the TG curve is less vertical around $312.0^{\circ} \mathrm{C}$; this is due to for biodiesel (100:0) practically all sample was decomposed at this temperature, while for SO sample, the decomposition was just beginning at $266.5{ }^{\circ} \mathrm{C}$. These observations show the

(b)

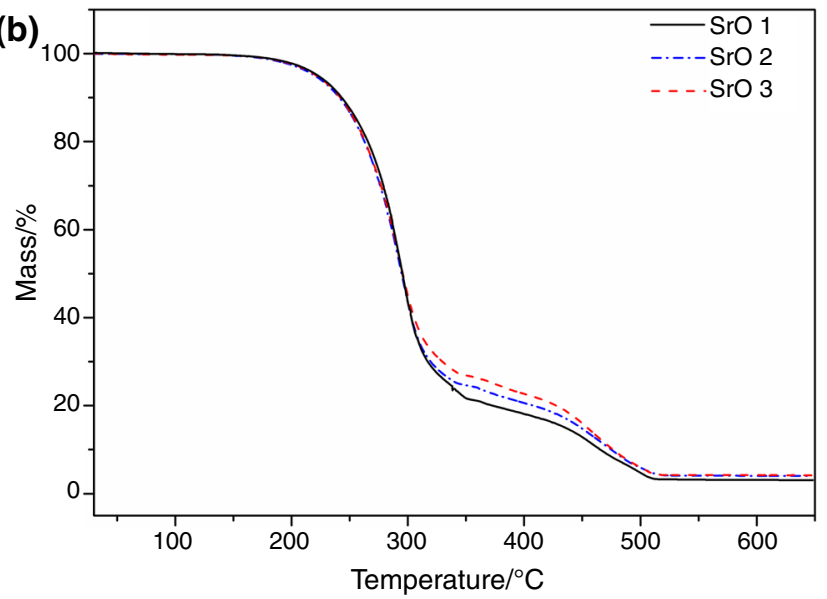

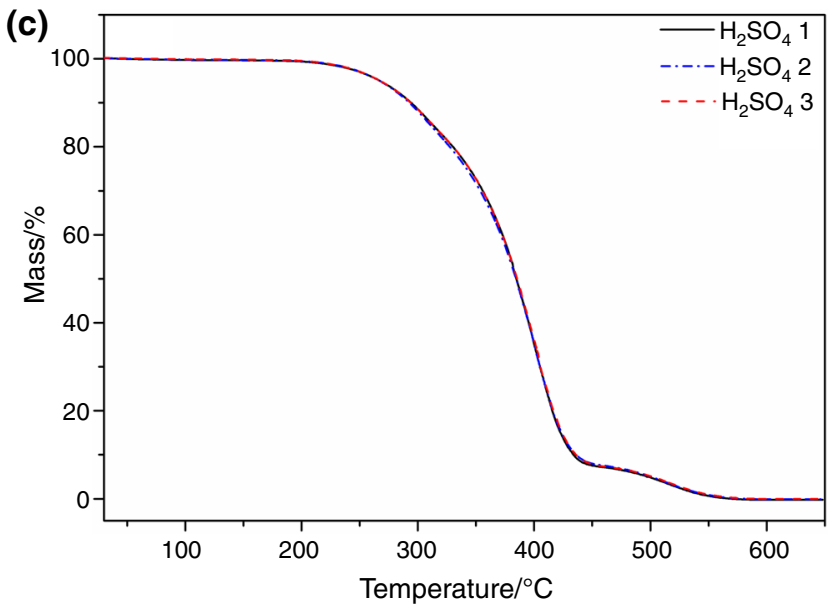

Fig. 3 TG Curves of product of transesterification reaction using $\mathrm{CaO}(\mathbf{a}), \mathrm{SrO}(\mathbf{b})$ and $\mathrm{H}_{2} \mathrm{SO}_{4}$ (c) as catalyst 

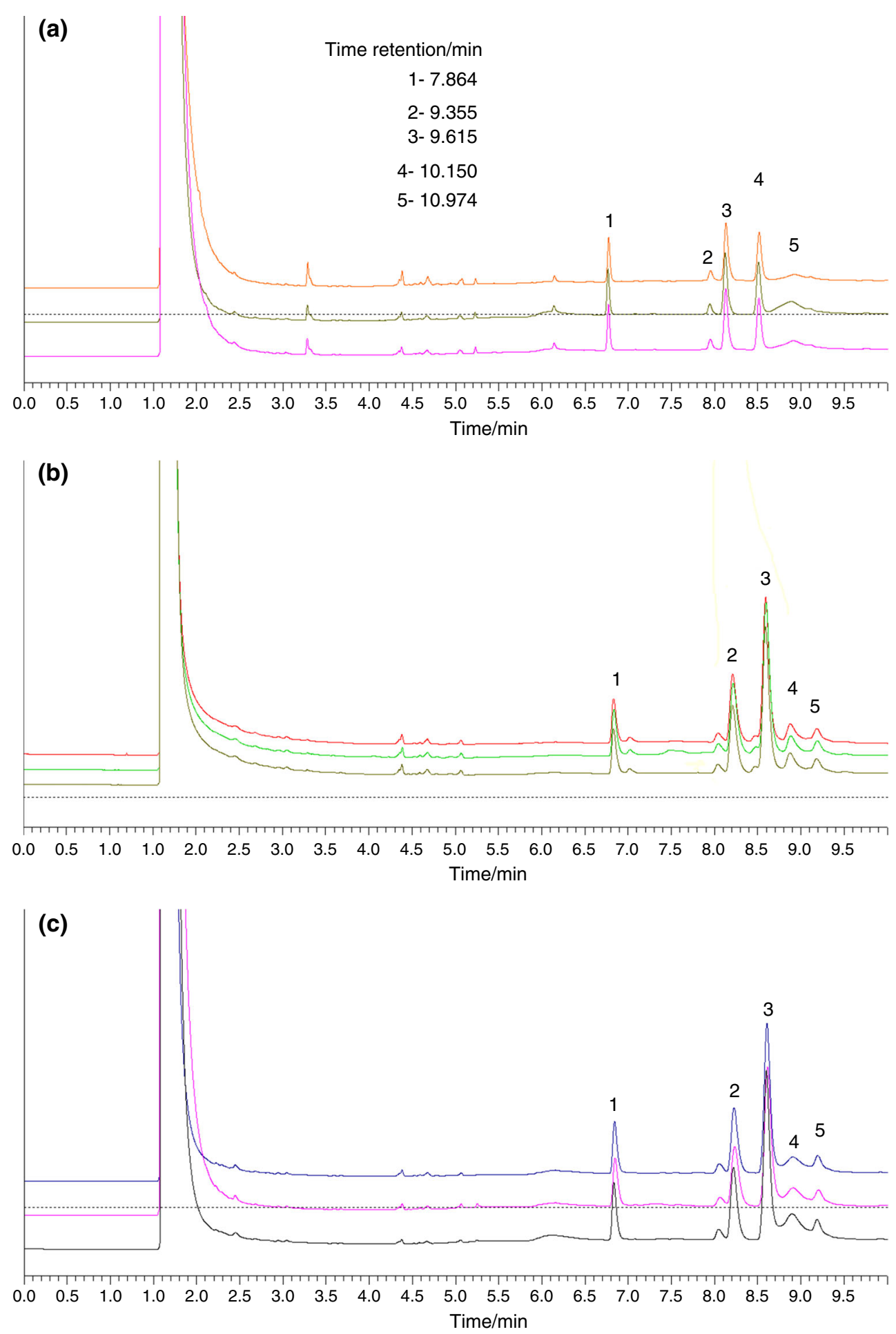

Fig. 4 Chromatograms obtained from product of transesterification reaction using $\mathrm{CaO}(\mathbf{a}), \mathrm{SrO}(\mathbf{b})$ and $\mathrm{H}_{2} \mathrm{SO}_{4}(\mathbf{c})$ as catalyst. The numbers refer to main methyl esters present in biodiesel from soybean oil: 1-palmitate, 2-stearate, 3-oleate, 4-linoleate, and 5-linolenate

importance of knowing the thermal behavior of the isolated compounds: raw material (SO) and biodiesel.

The degree of conversion values obtained for each sample by both techniques is exhibited in Table 2. The average DC values obtained by GC-FID and TG differ by no more than $3.53 \%$, and the standard deviation of both analyses is small. The $F$-test is used to compare the variance values, assuming the confidence interval equal to $95.0 \%$. All values of $F$ are less than the $F_{\text {critical }}$, demonstrating that the variance values of both techniques do not 


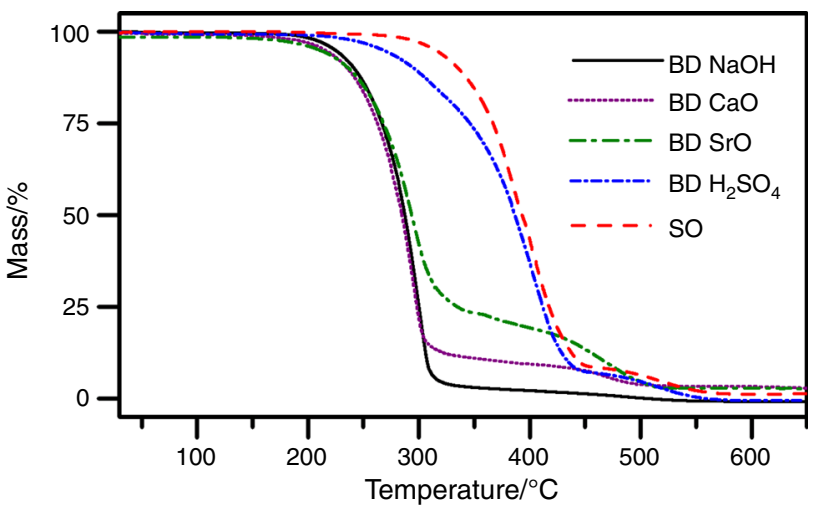

Fig. 5 TG Curves of biodiesel (BD) obtained with each catalyst and of soybean oil (SO)

Table 2 Values of degree of conversion (DC), average, standard deviation (SD), and $\mathrm{F}$ values obtained for each sample using $\mathrm{TG}$ and GC-FID

\begin{tabular}{|c|c|c|c|c|c|}
\hline Catalyst & Technique & $\mathrm{DC} / \%$ & Average/\% & SD & $F$-test \\
\hline \multirow[t]{6}{*}{$\mathrm{CaO}$} & TG & 74.26 & 74.59 & 0.58 & 1.5 \\
\hline & & 75.27 & & & \\
\hline & & 74.26 & & & \\
\hline & GC-FID & 73.86 & 74.09 & 0.46 & \\
\hline & & 74.63 & & & \\
\hline & & 73.79 & & & \\
\hline \multirow[t]{6}{*}{$\mathrm{SrO}$} & TG & 64.67 & 66.5 & 1.62 & 1.8 \\
\hline & & 67.10 & & & \\
\hline & & 67.73 & & & \\
\hline & GC-FID & 64.56 & 62.08 & 2.19 & \\
\hline & & 60.39 & & & \\
\hline & & 61.29 & & & \\
\hline \multirow[t]{6}{*}{$\mathrm{H}_{2} \mathrm{SO}_{4}$} & TG & 13.30 & 13.54 & 0.32 & 1.1 \\
\hline & & 13.91 & & & \\
\hline & & 13.41 & & & \\
\hline & GC-FID & 16.72 & 17.07 & 0.31 & \\
\hline & & 17.27 & & & \\
\hline & & 17.24 & & & \\
\hline
\end{tabular}

${ }^{\mathrm{a}} F_{\text {critical }}=19.0$

differ [21]. These results indicate that thermogravimetry could be used to determine the degree of conversion of soybean oil to biodiesel, independent of DC value. The statistic data are shown in Table 2.

\section{Conclusions}

The average degree of conversion values obtained by hermogravimetry using Eq. 1 differs by a maximum of $3.53 \%$ from the results acquired by the standard method, gas chromatography. The statistical data showed that the variance values obtained from both techniques are comparable, even when the degree of conversion was relatively low. These results demonstrate that hermogravimetry could be used to propose an equation to determine the degree of conversion of soybean oil to biodiesel in homogeneous and heterogeneous catalysis using Eq. 1, without knowing the ester content in sample.

Acknowledgements The authors wish to thank CAPES (Proc. 024/2012 Pro-equipment), CNPq (Proc. No. 421469/2016-1), POSMAT/UNESP and FAPESP (Proc. No. 2017/14936-9 and No. 2017/08820-8) for financial support and the Ph.D. Manoel Lima de Menezes for help.

\section{References}

1. Knothe G, Van Gerpen J, Krahl J, Ramos LP. Biodiesel manual. São Paulo: Edgard Blücher; 2006.

2. Baird C, Cann M. Environmental chemistry. 4th ed. New York: W. F. Freeman and Company; 2008.

3. OECD/Food and Agriculture Organization of the United Nations. OECD-FAO Agricultural outlook 2015, OECD publishing; 2015.

4. ASSOCIAÇÃO BRASILEIRA DE NORMAS TÉCNICAS. NBR 15764: Biodiesel—Determinação do teor total de ésteres por cromatografia gasosa; 2015.

5. DIN EN14103 Fat and oil derivatives- Fatty acid methyl esters (FAME) - Determination of ester and linolenic acid methyl esters content. Brussels: European Commitee for Standartization, Management Centre; 2011.

6. Henderson RK, Jímenez-González C, Constable DJC, Alston SR, Inglis GGA, Fisher G, Sherwood J, Binks SP, Curzons AD. Expanding GSK's solvent selection guide-embedding sustainability into solvent selection starting at medicinal chemistry. Green Chem. 2011;13:854-62.

7. Alfonsi K, Colberg J, Dunn PT, Fevig T, Jennings S, Johnson TA, Kleine HP, Knight C, Nagy MA, Perry DA, Stefaniak M. Green chemistry tools to influence a medicinal chemistry and research chemistry based organization. Green Chem. 2008;10:31-6.

8. Jain S, Sharma MP. Application of Thermogravimetric analysis for thermal stability of Jatropha Curcas biodiesel. Fuel. 2012;93:252-7.

9. Chien YC, Lu M, Chai M, Boreo FJ. Characterization of biodiesel and biodiesel particulate matter by TG, TG-MS and FTIR. Energy Fuels. 2009;23:202-6.

10. Dantas MB, Albuquerque AR, Barros AK, Rodrigues-Filho MG, Antoniosi-Filho NR, Sinfrônio FSM, Rosenhaim R, Soledade LEB, Santos IMG, Souza AG. Evaluation of the oxidative stability of corn biodiesel. Fuel. 2011;90:773-8.

11. Santos AGD, Souza LD, Caldeira VPS, Farias MF, Fernandes VJ Jr, Araújo AS. Kinetic study and thermoxidative degradation of palm oil biodiesel. Thermochim Acta. 2014;592:18-22.

12. Conceição MM, Fernandes VJ Jr, Araújo AS, Farias MF, Santos IMG, Souza AG. Thermal and oxidative degradation of castor oil biodiesel. Energy Fuels. 2007;21:1522-7.

13. Zhao H, Cao Y, Orndorff W, Cheng YH, Pan WP. Thermal behaviors of soy biodiesel. $\mathrm{J}$ Therm Anal Calorim. 2012;109:1145-50.

14. Jain S, Sharma MP. Thermal stability of biodiesel and its blends: a review. Renew Sustain Energy Rev. 2011;15:438-48.

15. Santos NA, Tavares MLA, Rosenhaim R, Fernandes Silva FC, Jr VJ, Santos IMG, Souza AG. Thermogravimetric and calorimetric 
evaluation of babassu biodiesel obtained by the methanol route. J Therm Anal Calorim. 2007;87:649-52.

16. Lima JRO, da Silva RB, de Moura EM, de Moura CVR. Biodiesel of tucum oil, synthesized by methanolic and ethanolic routes. Fuel. 2008;87:1718-23.

17. Chand P, Reddy CV, Verkade JG, Wang T, Grewell D. Termogravimetric quantification of biodiesel produced via alkali catalyzed transesterification of soybean oil. Energy Fuels. 2009;23:989-92.

18. Souza FP, Luciano MA, Pasa VMD. Termogravimetry and viscometry for assessing the ester content (FAME and FAEE). Fuel Process Technol. 2013;109:133-40.
19. Gaglieri C, Caires FJ, da Silva DJ, Bertholdo R, Mendes RA. Synthesis, thermal behaviour and catalytic study of Ni-chitosan in transesterification reaction using soybean oil. Braz J Therm Anal. 2017;6:1-6.

20. Hartman L, Lago RCA. Rapid preparation of fatty acid methyl esters from lipids. Lab Pract. 1973;22:475-6.

21. Menezes ML, Lopes LFS, Passaretti Filho J. Síntese de biodiesel empregando óleo de abacate. Rev Anal. 2010;44:68-78.

22. Miller JN, Miller JC. Statistics and chemometrics for analytical chemistry. 6th ed. Harlow: Pearson Education Limited; 2010. 